\title{
Alla Prima: o corpo agora
}

\author{
IVANA MENNA BARRETO
}

This article analyzes the performance Alla Prima, by Tiago Cadete, a Portuguese artist residing between Portugal and Brazil. The work was presented at the Sesc Biennial of Dance 2017 in Campinas. "Alla Prima" is an Italian expression that could be translated as "à la primera", or "de primera". It is used to designate a technique or style of painting in which the paint is applied directly to the base chosen, without studies or preparation, and the final result is reached after a single application, without touching the artist. The performance shows a dance from the dismantling of a body already given, printed in the collective memory in images documented on screens and authorized over time. These images were curiously presented by history as documents, records of the colonial period. Performance, however, diverts our gaze from the whole to the parts, to certain details of these images, to the way they are constructed from each artist's point of view - and in this deviation lies their strength. We see the deconstruction of an idea of Brazil in a body. Is Brazil a country, or the built image of a country? Is the Brazilian body a pictorial, textual, sound invention?

PERFORMANCE / PAINTING / BODY / DECONSTRUCTION / DANCE

Alla Prima é uma expressão italiana que poderia ser traduzida como «à primeira», ou «de primeira». É utilizada para designar uma técnica ou estilo de pintura na qual a tinta é aplicada diretamente na base escolhida, sem estudos nem preparação, e o resultado final é atingido após uma única aplicação, sem retoques do artista. Praticada a partir do século XVII, originalmente com tinta a óleo, a pintura é realizada e terminada enquanto a tinta ainda está fresca.

De primeira, no primeiro golpe, sem retoques, no ato. É assim, com essa impressão de que tudo pode se fazer agora, com esse cheiro de tinta fresca, que penso em Alla Prima, performance de Tiago Cadete apresentada na segunda noite da Bienal Sesc de Dança 2017 em Campinas. Penso no homem nu que se move num espaço restrito, recortado pela luz de um projetor. Ele transita entre posturas que imitam as pinturas 
projetadas de um computador diretamente para o seu corpo; ao observá-las, escolhe um personagem ou gesto específico para reproduzir. Ao longo da performance, o processo das reproduções vai construindo uma coreografia de gestos montados pelas improvisações feitas «à primeira». Além da pintura, ouvem-se eventualmente áudios que dialogam com o contexto das telas.

Segundo o artista, os textos falados são descrições de artistas visuais sobre algumas imagens escolhidas por ele. Ele mostrou as imagens e pediu aos artistas a descrição, tendo como ponto de partida o corpo nela contido - por isso o conteúdo muda conforme muda a imagem. Já as imagens foram escolhidas junto com o consultor de história da arte do projeto, e posteriormente foram realizadas sequências reproduzidas pelo seu corpo. À sua frente ele consegue ver a tela do computador emitindo as mesmas imagens projetadas. Não há propriamente improvisação, mas escolha, e ele vai, então, alternando os corpos da imagem; por vezes uma imagem tem dois corpos, nesse caso escolhe no momento o que quer fazer. Cadete performa, portanto, o gesto que vê na tela de computador à sua frente. As personagens são escolhidas por sua diversidade - homens, mulheres, crianças, negros, indígenas, portugueses, emigrantes japoneses. São muitos os corpos que dão corpo a Alla Prima.

$\mathrm{O}$ artista português, residente entre Portugal e Brasil, dança este país com um corpo inquieto, como quem o vê pela primeira vez, mas não o Brasil enquanto natureza. Há uma escolha nitidamente pela cultura, pela pesquisa sobre o que já foi criado e pensado por alguém - e esta memória é ativada para ganhar outras cores no presente. Cadete descortina uma paisagem na própria pele ao acolher nela as projeções das pinturas já contaminadas pelo olhar de outros criadores. Seu corpo segue nu, não pintado pelas tintas propriamente, mas virtualmente habitado pelas muitas imagens construídas ao longo de séculos - e que compartilhamos enquanto espectadores ao mesmo tempo em que ele as experimenta. Este procedimento é crucial para o trabalho, que não se detém na primeira camada do que seria o Brasil, mas ao contrário, escolhe criticamente olhares diferenciados de artistas que pintaram os descobrimentos e a colonização. Deste modo, junto com as pinturas projetadas podemos perceber os detalhes dos pontos de vista impressos nas pinturas, escolhidos pelo performer; e ainda as vozes de atores nos áudios, comentando pontualmente o universo das telas.

O que vemos é, então, mediado pelo tempo, pelas imagens evocadas através dos séculos e, sobretudo, pelo tempo da atuação de Cadete, de 
sua rápida escolha a cada gesto, pela percepção que lhe permite acessar algumas situações retratadas nas telas. A escolha dos gestos parece ser rápida, mas na verdade não é disso que se trata (de velocidade). Trata-se mais que tudo de uma precisão, uma urgência em dizer as obras (e qual Brasil há nelas) de um modo próprio e necessário.

Revendo as pinturas de Pedro Américo, Debret, Vítor Meireles, Rodolfo Amoedo, Portinari, José Maria de Medeiros, entre outros, percebemos um encobrimento do Brasil, ou do que poderia ser um país livre: Tiradentes esquartejado, escravos negros segregados à mesa de jantar, o trabalhador mestiço com as mãos grandes e as unhas sujas, a bela índia nua retratada como virgem dos lábios de mel (impossível não lembrar que Iracema, apropriada romanticamente pela beleza, é também o anagrama de América). A cruz católica desde o início, elevada em Porto Seguro, e a primeira missa, feita por homens brancos vestidos com muitas roupas, configuram um espetáculo curioso quando desviamos o olhar para os índios nus que o observavam.

Os corpos dos índios estavam nus e sem vergonha, como este agora, em cena, exposto ante os espectadores. Há, no entanto, uma diferença entre as duas situações: os corpos dos índios retratados nas telas estavam observando o espetáculo, enquanto este corpo do agora performa o que vê nas imagens, buscando os pedaços de um quebra-cabeças que ficou perdido na história entre Brasil e Portugal.

Aos poucos vamos reencontrando, nas pinturas impressas no corpo do artista, as mesmas imagens que vimos nos livros da infância, descritas à época como retratos das grandes batalhas em que alguns heróis deram a própria vida pela conquista de territórios. No entanto, em pinturas como A batalha do Avaí, de Pedro Américo, não há exatamente cenas heroicas, mas sangrentas: cavalos e cavaleiros caídos, corpos em desespero, impotentes, misturados aos mortos; e o horror nos olhos de mulheres e crianças, vacas e animais feridos. O lugar que vemos não é o Brasil «grande», mas um céu encoberto pelas nuvens, uma atmosfera infernal, vermelha, feita de barbárie, armas, foices e medo.

Vemos a desconstrução de uma ideia de Brasil num corpo. O Brasil é um país, ou a imagem construída de um país? O corpo brasileiro é uma invenção pictórica, textual, sonora?

Alla Prima mostra uma dança a partir do desmonte de um corpo já dado, impresso na memória coletiva em imagens documentadas e autorizadas ao longo do tempo. Essas imagens foram, curiosamente, apresentadas pela história como documentos, registros do período colonial. 
A performance, porém, desvia o nosso olhar do todo para as partes, para certos detalhes dessas imagens, a maneira como são construídas pelo ponto de vista de cada artista - e neste desvio reside sua força.

A desconstrução é uma ponte para a relação com nosso presente: a violência, a segregação, as tentativas de domesticação do pensamento feitas pela religião, e de controle dos territórios pelas batalhas sangrentas, que evidenciam mortes seletivas, preferencialmente de negros e pobres. Nosso fracasso quando se trata de conviver e agir coletivamente parece vir de muito longe, e é reforçado pela ideia de unidade conseguida pela imposição da força. Não se trata aqui apenas da força física, mas também da apropriação de uma estética para legitimar a versão da história que valorizou o todo das imagens (como documentos históricos), em detrimento da interpretação de suas partes (como pontos de vista dos artistas envolvidos na criação das telas).

Muito do que somos e do que vivemos está no que não foi dito - é o que mostram os gestos de Cadete à medida que se articulam na dinâmica de uma improvável coreografia. Poderíamos pensar, assistindo à sua atuação, que se trata tanto de coreografia quanto de cinema - como processo artesanal de fotomontagem, de imagens em ação. As imagens não são postas em jogo apenas para serem observadas e apreciadas, mas para serem recriadas, dinamizadas. São recompostas a partir do que não está nelas, do que nelas foi silenciado.

O silenciamento é uma operação política, que se vale de diferentes estratégias. Jacques Rancière diz que «a política ocupa-se do que se vê e do que se pode dizer sobre o que é visto, de quem tem competência para ver e qualidade para dizer, das propriedades do espaço e dos possíveis do tempo» (Rancière, 2005: 16-17). A operação de desmontagem feita no corpo de Tiago Cadete, nas pausas em que recorta cada gesto, e depois na maneira como os articula, no mix das imagens do jantar brasileiro, da primeira missa, da batalha do Avaí, de Iracema. etc., deixa entrever o que não faz parte do título das telas: a contundência das situações, do contexto, da cor das tintas. Sua ação faz parte de outra política, a que interfere pelas bordas, não se anuncia como manifesto ou panfleto, nem mesmo ocupa todo o palco. Vincula-se a outra forma de ação - a de um trabalho que escava um lugar e limpa sua poeira, para jogar luz no que nele já existia, mas não era visto. Neste caso o espaço criado pela performance não é físico, mas de pensamento; e o tempo é estratégia de deslocamentos, entre o passado revisitado e o agora que se abre ao que está por vir. 
Ao pensar nas imagens de um corpo fragmentado (segregado pelas diferenças sociais), de onde viemos, e no corpo em ação de Tiago Cadete, que nos provoca com uma articulação dessas imagens no mesmo tempo-espaço, é possível vislumbrar o momento que vivemos. Este momento nos fala de um desconhecimento sobre o que somos, e é curioso ver um artista português recontando essa história de outro jeito, com o próprio corpo nu disponível para se deixar impregnar das imagens do sangue, do medo, da ironia que foi contar a história de um país durante séculos sob a perspectiva do colonizador. Essa perspectiva se fortaleceu pela valorização da narrativa dos corpos dos índios sentados, apreciando a primeira missa; pela ocultação do sofrimento da escravidão nas tintas descritivas do «jantar brasileiro»; pelas telas que se tornaram documentos das batalhas pela conquista de um grande território - como se a grandeza estivesse na geografia e na dominação física.

A ocupação de um território não parece ser a questão central de Alla Prima. A ação se realiza num espaço mínimo: um recorte dentro de um palco, que não era o maior do festival. No entanto o artista mostra, nesse pequeno espaço, uma ideia que cresce por muitos prismas, durante o tempo em que se apresenta. Logo ao entrar, vestido com bermudas, camiseta e tênis, despe-se, olha para a tela que projeta as imagens e a partir daí inicia uma aventura num só fôlego, sem pressa, apropriando-se a cada gesto de um passado que nos incomoda.

O incômodo é parte do problema trazido pela performance, que dele se alimenta - é parte da experiência que partilhamos enquanto o artista se move. A performance parece nos dizer que não fomos ao teatro, ou à Bienal de Dança em Campinas para sermos felizes, mas para experimentarmos algo. A experiência de nos confrontarmos com um passado que preferimos esquecer tem a força de um desafio, de trilhar um caminho que pode ser potente quando experimentado coletivamente.

Tania Rivera defende que a experiência não está associada à felicidade, nem é um encontro «entre o eu e o mundo»: «ela não se identifica com um instante de felicidade (ou infelicidade). Ela talvez nunca se apresente de frente, mas sempre de viés e fora da hora» (Rivera apud Bident et al., 2012: 85). Rivera acredita que a experiência seria «principalmente aquela do desconforto (o Unbehagen de Freud) e da estranheza familiar que nos define» (idem). Este desconforto seria o que nos faz sair de nós mesmos, porque é algo que está fora de nós, mas com o qual nos identificamos. Neste sentido, o estranhamento da arte é uma forma de tirar-nos de uma zona de conforto para lançar-nos no mundo, e no desconhecido que há em nós. 
Ao abordar a passagem entre o dentro e fora, Rivera lembra que esta é uma questão «importante para a arte brasileira, especialmente a partir de Lygia Clark» (idem, 88) e que «a passagem do que é íntimo ao que é do outro (êxtimo, fora de si, no neologismo de Lacan) implica uma torção, uma subversão, de modo imprevisível, sempre experimental» - e essa experiência poderia ser compreendida «como definição da própria cultura» (ibidem, 88). A cultura, então, seria este sair de si que a experiência requer - e a passagem entre o dentro e o fora vem mediada pelo corpo. Não somos, neste caso, os agentes da experiência, mas ao contrário, é a situação de experiência e o mundo que nos experimenta.

O estranhamento e o incômodo que podemos sentir diante das imagens das pinturas/referências de Alla Prima fala muito sobre um país que criamos ao longo dos séculos, esse que queremos esquecer, ou desconhecer, porque é sangrento, violento, segregador. A performance, contudo, provoca uma reflexão além das pinturas e do tempo que retratam, já que acontece na dinâmica dos gestos, na maneira como, a cada pausa ou investida do braço ou do torso do artista o corpo se lança ágil, ou irreverentemente, no espaço. Esse tempo da reconfiguração, ou recomposição, vem misturado às percepções de Cadete, e às nossas enquanto o observamos, quando rimos deste ou daquele gesto - e talvez por isso o incômodo possa ser confrontado neste momento, porque pensamos e revisitamos nossa memória acompanhados. O corpo da ação performática se reinventa, abrindo espaços para a reinvenção do corpo-país.

A crítica de arte Catherine Millet, ao comentar o conceito de estética relacional, de Nicolas Bourriaud, pondera que não se trata apenas da participação do espectador, como foi interpretado por alguns:

[Alarga] para o sujeito social a ideia de invenção de si, proposta por Harold Rosenberg para explicar o action painting, ao mesmo tempo em que radicaliza a autonomia do gesto em relação ao objeto. Daí sua valorização dos procedimentos, sua ambição de parasitar o elo social, em detrimento do objeto finalizado que Bourriaud chama de monumento. (Millet apud Bourriaud, 2015: 10)

Millet vislumbra, na proposição de estética relacional de Bourriaud, um alargamento da ideia de invenção de si para o elo social, deslocando a arte daquilo que Bourriaud chamou de «monumento» (ou objeto de arte) para a aproximação com procedimentos que estabelecem vínculos sociais. A arte não estaria, nesta compreensão, naquilo que a separa do 
comum e, de certa forma, a sacraliza - mas no percurso das relações inter-humanas. Neste percurso as formas podem ser elaboradas, quando a estética se aproxima da ética.

O percurso das relações inter-humanas, no caso de Alla Prima, está impresso nas tintas das telas, e também projetado no corpo de Cadete, que mobiliza as pinturas para provocar questões sobre seus pontos de vista. $\mathrm{O}$ que está em jogo neste percurso é a maneira como se estabelecem as relações, entre corpo e memória, e entre artista e sociedade.

Bourriaud considera que «o que está desaparecendo sob nossos olhos é apenas essa concepção falsamente aristocrática da disposição das obras de arte, ligada ao sentimento de adquirir um território» (Bourriaud, 2009: 20). Assim, a obra se apresentaria menos como um território demarcado, e mais como «uma duração a ser experimentada, como uma abertura para a discussão ilimitada» (idem, 20-21). Podemos dizer que a passagem proposta por Bourriaud, da obra-objeto (monumento) a uma «abertura para a discussão ilimitada» é significativa em Alla Prima, que se expande enquanto proposição do corpo como lugar de atravessamentos, de tempos, estéticas e relações sociais.

A invenção de si se alarga para o sujeito social, como disse Millet, quando o artista se coloca na situação de performer e espectador (já que observa as obras e as experimenta no corpo simultaneamente), enquanto é visto pelos espectadores sentados na plateia. Além da obra «dentro da obra» há um corpo que se avoluma, este outro corpo-país, formado pelas pinturas; pelo performer em ação transformando o que vê nas pinturas; e pelos espectadores, experimentando os deslocamentos propostos pela performance.

A conversa proposta por Alla Prima pode ser vista como uma crítica da nossa história com os portugueses, do que foi essa relação e do que ela poderia ser. Mas é também a experiência de um corpo que se reinventa pela própria exposição, quando sai de si para experimentar outros corpos; e abre espaço para uma leitura da nossa história que costuma ser encoberta. Esse encobrimento passa pela desconfiança em relação à nudez, pela maneira como deixamos de ser índios e assumimos as roupas do colonizador, pelo medo.

Alla Prima diz que precisamos reaprender a olhar para o Brasil, buscar o gesto possível para dizer o que ainda não pôde ser dito. Ao abrir espaço para este gesto, a performance opera como elo entre corpo e história, ética e estética, enfrentando o tempo agora. 


\section{REFERÊNCIAS BIBLIOGRÁFICAS}

BOU RRIAUD, Nicolas (2009), Estética relacional, São Paulo, Martins Fontes.

MILLET, Catherine (2015), «Préface» in Nicolas Bourriaud, Les grands entretiens d'artpress, Paris, Artpress.

RANCIÈRE, Jacques (2005), A partilha do sensivel: estética e política, São Paulo, Edições 34 .

RIVERA, Tania (2012), «Experiência (revirada)», in Renato Rezende, Ana Kiffer e Christophe Bident, Experiência e arte contemporânea, Rio de Janeiro, Editora Circuito.

\section{IVANA MENNA BARRETO}

É criadora e investigadora carioca. Os seus projectos criam percursos para se encontrar pessoas e lugares. Doutorada em Comunicação e Semiótica pela Pontifícia Universidade Católica de São Paulo (PUC-SP) e pós-doutorada em Dança pelo PPG Dança/ /Universidade Federal da Bahia, é professora de Dança e Movimento do curso de Licenciatura em Teatro da Universidade Federal do Estado do Rio de Janeiro (UNIRIO). 